\title{
NARRATIVAS EM HIPERMÍDIA PARA AMBIENTES VIRTUAIS INCLUSIVOS: UM ELO ENTRE SURDOS E OUVINTES
}

\section{NARRATIVES IN HYPERMEDIA FOR LEARNING MANAGEMENT SYSTEM: A LINK BETWEEN TO DEAF AND HEARING}

\author{
Silvia Regina Pochmann de Quevedo \\ Universidade Federal de Santa Catarina \\ silviareginaquevedo@gmail.com \\ Tarcisio Vanzin \\ Universidade Federal de Santa Catarina \\ tvanzin@gmail.com
}

Palavras-chaves: narrativas, hipermídia, surdos

\begin{abstract}
Este artigo apresenta a experiência do uso de narrativas junto a alunos surdos e ouvintes na perspectiva da inclusão e da hipermídia. A possibilidade de apresentar um mesmo conteúdo instrucional em diferentes linguagens compõe discursos diferenciados. Cada tipo de discurso narrativo pode ser percebido como mais acessível ou inteligível por alguns usuários e menos por outros. O método utilizado baseou-se na Análise do Discurso proposta por Norman Fairclough, com foco na sintaxe utilizada pelos participantes e na tomada de turnos em Grupo Focal, com posterior verificação da aprendizagem. O estudo demonstrou limites da hipermídia em narrativas e recomendações para sua construção em AVEAs inclusivos. A narrativa em hipermídia baseada na argumentação técnica e dissertativa prevaleceu sobre os demais gêneros narrativos como a forma preferida de aprendizagem para surdos e ouvintes.
\end{abstract}

\section{Keywords: narratives, hypermedia, deaf}

This article presents the experience of using narratives with deaf and hearing students from the perspective of inclusion and hypermedia. The possibility of presenting the same instructional content in different languages composes differentiated discourses. Each type of narrative discourse can be perceived as more accessible or intelligible by some users and less by others. The method used was based on the Discourse Analysis proposed by Norman Fairclough, focusing on the syntax used by the participants and the turn-taking in Focal Group, with subsequent verification of learning. The study demonstrated limits of hypermedia in narratives and recommendations for its construction in inclusive Learning Management Systems. The narrative in hypermedia based on technical and dissertative argumentation prevailed over the other narrative genres as the preferred form of learning for the deaf and hearing.

\section{Introdução}

Do suporte físico ao virtual, constituído a partir do século $\mathrm{XX}$, as narrativas se mantêm imprescindíveis. Ficcionais ou não, retratam a vida, servem de espelho, permitem investigar sentimentos, discursos, relações de poder. Bruckmeier e Harré [2016] enfatizam que seu interesse científico advém da consciência de que elas constituem um parâmetro holístico - 


\section{$16^{\circ}$ \\ ERGODESIGN USIHC CINAHPA}

$16^{\circ}$ Ergodesign - Congresso Internacional de Ergonomia e Usabilidade de Interfaces Humano Tecnológica: Produto, Informações Ambientes Construídos e Transporte

$16^{\circ}$ USIHC - Congresso Internacional de Ergonomia e Usabilidade de Interfaces Humano Computador

CINAHPA | 2017 - Congresso Internacional de Ambientes Hipermídia para Aprendizagem. linguístico, psicológico, cultural e filosófico fundamental na tentativa humana de explicar a natureza e as condições do sentido da existência.

Cada tipo de discurso narrativo pode ser percebido como mais acessível ou inteligível por alguns usuários e menos por outros. Quais narrativas seriam mais adequadas na estruturação de um conteúdo? Existiria uma narrativa mais confortável a esse público alvo? Narrativas em hipermídia para surdos e ouvintes propõem um mundo convergente à inclusão.

"O princípio fundamental da educação inclusiva é que todos os alunos devam aprender juntos, independente de quaisquer dificuldades ou diferenças" [CAMPBELL, 2009, p.141]. Para Campbell [2009, p.142], "se aceitarmos alunos deficientes em uma escola para todos e se eles forem tratados de modo excludente, teremos uma farsa de inclusão".

Desenvolver os Ambientes Virtuais de Ensino Aprendizagem (AVEAs) sob esse prisma exige, como em toda nova linguagem, "um momento de desenvolvimento técnico ao domínio dos mecanismos expressivos" [MURRAY, 2003]. "Via de regra, existe um período de adaptação gradativa do novo até que o desenho de funções se instale, ou ocupe seu espaço" [SANTAELLA, 2007, p. 288].

Somente ultrapassado o período de pioneirismo é que uma nova linguagem propicia domínio de uso. Com as narrativas em hipermídia não é diferente. Daí a importância em modelá-las em novos padrões de linguagem para uso em AVEAs por meio da internet. O paradigma da inclusão é um componente a mais na importância de seu desenvolvimento.

\section{Resultados}

$\mathrm{Na}$ sessão em que os participantes da pesquisa testaram todas as narrativas o Grupo Focal foi realizado com oito alunos. Os testes para esse dia foram organizados da seguinte forma: para não haver 'risco de contaminação' dos resultados, todos teriam que passar por todas as narrativas. Sequências de ordens diversas foram montadas

\section{Método}

A pesquisa foi realizada junto a 26 alunos, entre surdos e ouvintes, que ao longo de quatro sessões, testaram as narrativas em hipermídia elaboradas ao AVEA WebGD Acessível, desenvolvido por pesquisadores da Universidade Federal de Santa Catarina (UFSC) para o ensino de Geometria Descritiva.

Os participantes da pesquisa dominavam Libras e/ou Língua Portuguesa. As três narrativas do ambiente foram experimentadas: História em Quadrinhos (N1), Contos (N2) e a Narrativa Dissertativa (N3), esta última baseada na argumentação e linguagem direta de exposição do conteúdo técnico.

O sistema teve o fluxo de navegação concebido a partir de mapa mental. Conforme o mapa, utilizado pela equipe de implementação, o usuário poderia entrar e sair das narrativas, realizando exercícios propostos ao final de cada uma delas. Cada narrativa (com exceção da HQ, com apenas um final) é composta por um veio principal da história, um secundário, dois finais, e atividades.

Em caso de acerto da atividade, o participante é conduzido ao final da narrativa para retornar ao menu inicial; em caso de erro à próxima narrativa, e assim sucessivamente até chegar à terceira narrativa. Com a repetição do erro, o sistema foi programado para entrar em looping, momento de interferência do tutor ou professor para auxiliar no processo de ensino aprendizagem.

com N1, N2 e N3 e sorteadas. Cada participante tirou de um envelope um papel com a combinação a ser seguida.

A testagem contou com três surdos com domínio do código Libras, três ouvintes com domínio de Português e Libras, e dois ouvintes que não conheciam Libras. A atividade começou às $19 \mathrm{~h}$ e encerrou às $23 \mathrm{~h}$.

Buscou-se identificar nos roteiros das gravações os
Realização:

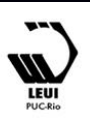




\section{$16^{\circ}$ \\ ERGODESIGN USIHC CINAHPA}

verbos gostar, conseguir e entender que apareciam na fala de cada participante, com a elaboração de quadros contendo a hora exata da fala e o autor da declaração. $\mathrm{O}$ verbo mais utilizado foi entender, deixando claro que as narrativas foram compreendidas. A pesquisa indicou que os ouvintes proposicionaram bem mais do que os surdos, com os primeiros elaborando 255 enunciados e os segundos em número bem inferior de exposições: 73 enunciados, o que permitiu verificar o predomínio da fala de ouvintes sobre surdos e investigar as razões desse resultado.

Entre os alunos surdos, 51 enunciados aparecem relacionados a sentenças positivas, 13 a negativas, quatro a positivas e negativas, cinco são de função fática, totalizando 73 enunciados. Entre os ouvintes, 181 são relativos a sentenças positivas e 67 a negativas; cinco enunciados são positivos e negativos e dois de ordem fática, num total de 255 enunciados.

O extrato abaixo apresenta as falas de um aluno surdo e de dois ouvintes oriundas do roteiro decupado das gravações do Grupo Focal. A análise da sintaxe aponta verbos, advérbios, adjetivos e pronomes indefinidos utilizados, indicativo das referências positivas sobre o ambiente hipermidiático proposto.

Felipe/Intérprete: [...] Eu vi que tinha ligação (entre a narrativa e as atividades), eu entendi bem, não me atrapalhou. Me ajudou a pensar os conceitos, a lembrar, consegui ligar com a atividade as informações.

Cássio: [...] Achei ótima a estratégia de vincular o conceito a uma história. [...] Não é só matemática [...] isso me agradou. E também achei muito interessante utilizar histórias que tenham a ver com a cultura do surdo, como o Leppé, por exemplo, tem tudo a ver. [...] Ah, eu achei legal o fundo moral da história... 'se você sonha, você pode criar' ... achei interessante isso.

Nina: Ficou bom tanto para o surdo quanto para o ouvinte, quanto para o jovem, quanto para o adolescente. Ficou bom para todo $16^{\circ}$ Ergodesign - Congresso Internacional de Ergonomia e Usabilidade de Interfaces Humano Tecnológica: Produto, Informações Ambientes Construídos e Transporte

$16^{\circ}$ USIHC - Congresso Internacional de Ergonomia e Usabilidade de Interfaces Humano Computador

CINAHPA | 2017 - Congresso Internacional de Ambientes Hipermídia para Aprendizagem.

As sentenças negativas apontaram os problemas do ambiente, com a utilização de adjetivos como "difícil", "confuso", "cansativo". A fala do aluno surdo Felipe transcrita abaixo indica que não foi fácil para ele percorrer a última narrativa que lhe coube no sorteio, a N2, relativa aos Contos, por considerar os textos muitos extensos. Para a aluna ouvinte Nina, foi a repetição do conteúdo que não agradou. A ouvinte Jade também ponderou que os textos poderiam ser menores.

Felipe/Intérprete: Eu vi a história em quadrinhos, a narrativa e vi a narrativa descritiva (dissertativa). Eu vi essa, vi a narrativa descritiva, as outras narrativas de contos eu já estava bem cansado. Assisti um pouquinho, porque eram muito longas, daí as mais extensas... eu vi rápido o português e fui passando.

Nina: Eu achei cansativo, não sei se porque o tema era igual. Era sempre a mesma coisa. Pensei: "Que saco não aguento mais ver a mesma história, já gravei matemática inteira e não cheguei ao final do negócio. Só achei meio cansativo o tema, mas o resto normal.

Jade: É, podia ter uns textinhos menores com mais desenhos, mesmo que fossem mais quadros, pelo menos ia ser menos cansativo.

Felipe/Intérprete: Os contos (é que são extensos). É que tem que ficar assistindo, cansava muito. [...] (grifo nosso)

A aluna surda Isabel pede vírgulas, que em Libras são pausas. Elas são importantes, como afirmaram os alunos, para dar ritmo à narrativa e torná-la menos cansativa. Os alunos ouvintes conhecedores de Libras e os alunos surdos afirmaram que a HQ deveria ser apresentada em Libras e não apenas em português, para maior conforto de quem domina a 


\section{$16^{\circ}$ \\ ERGODESIGN USIHC CINAHPA}

língua de sinais.

A repetição intencional do conteúdo para oferecer diferentes formas de aprendizagem, segundo os participantes, é um motivo a mais para existirem muitas narrativas. $\mathrm{O}$ fato foi reconhecido como estratégia apropriada para a Educação a Distância (EAD) ou qualquer AVEA. Os alunos sugeriram uma 'bolsa de atividades' independente e comum a todas as narrativas.

Embora tenham aprovado os caminhos alternativos aos veios principais das histórias, ouvintes e surdos confirmaram dificuldades com a navegação, que não foi tranquila para três ouvintes: Cássio, Nina e Nelson, e uma aluna surda, Ingrid. Os alunos disseram que se perderam na navegação, que sentiram falta de mais indicativos para ela no design, o que gerou um sentimento de insegurança, confusão e perda de tempo.

A observação das gravações quanto à tomada de turnos indica a correlação de forças na disputa pela fala, o que demonstrou como se deu a exclusão dos alunos surdos na discussão. Em várias situações eles foram ignorados, apesar de o grupo ser pequeno, estar disposto em roda, haver duas intérpretes e participantes que dominavam os dois códigos de língua.

O fato demonstrou que a fala do surdo não é 'registrada'. Eles sinalizam, mas a transcrição dos vídeos indicou que não são traduzidos e suas ideias se perdem em meio à supremacia das vozes dos ouvintes. Em 14 enunciados, Felipe, Ingrid e Isabel não foram percebidos. Eles tentam expor seu pensamento, mas não são considerados.

Sentados lado a lado, os surdos Isabel, Ingrid e Felipe (da esq.p/dir.) tentam dizer que não acharam difícil fazer a atividade da Narrativa Dissertativa (N3), mas um ouvinte se sobrepõe e eles não são traduzidos. A Figura 1 demonstra o momento em que isso ocorre pela gravação da câmera exclusiva aos surdos. As intérpretes estão atentas, mas tudo acontece muito rápido, a sinalização da Libras é perdida, o que deixa os alunos surdos em desvantagem na discussão. $16^{\circ}$ Ergodesign - Congresso Internacional de Ergonomia e Usabilidade de Interfaces Humano Tecnológica: Produto, Informações Ambientes Construídos e Transporte

$16^{\circ}$ USIHC - Congresso Internacional de Ergonomia e Usabilidade de Interfaces Humano Computador

CINAHPA | 2017 - Congresso Internacional de Ambientes Hipermídia para Aprendizagem.

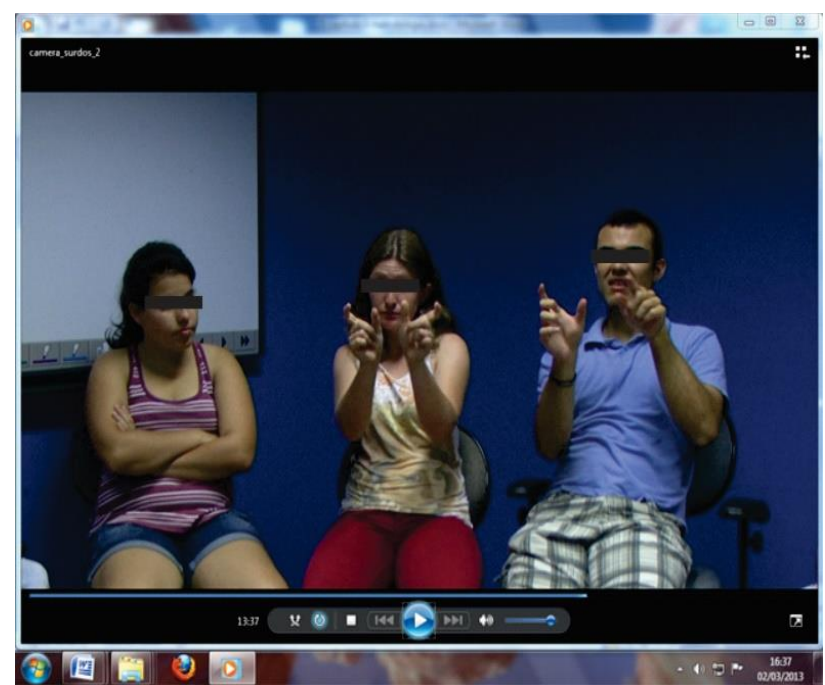

Figura 1: Em vão, alunos surdos tentam falar ao grupo

Fonte: Os autores

As imagens mostram que a reação dos alunos surdos diante desse quadro. Isabel se cala, cruza os braços. Felipe se impõe. Chama a atenção da intérprete, disputa o turno com a aluna ouvinte: levanta a mão, tenta estabelecer regras para as intervenções. Ingrid levanta a mão, hesita, depois sorri consternada, e se cala (Figuras 2 e 3 ).

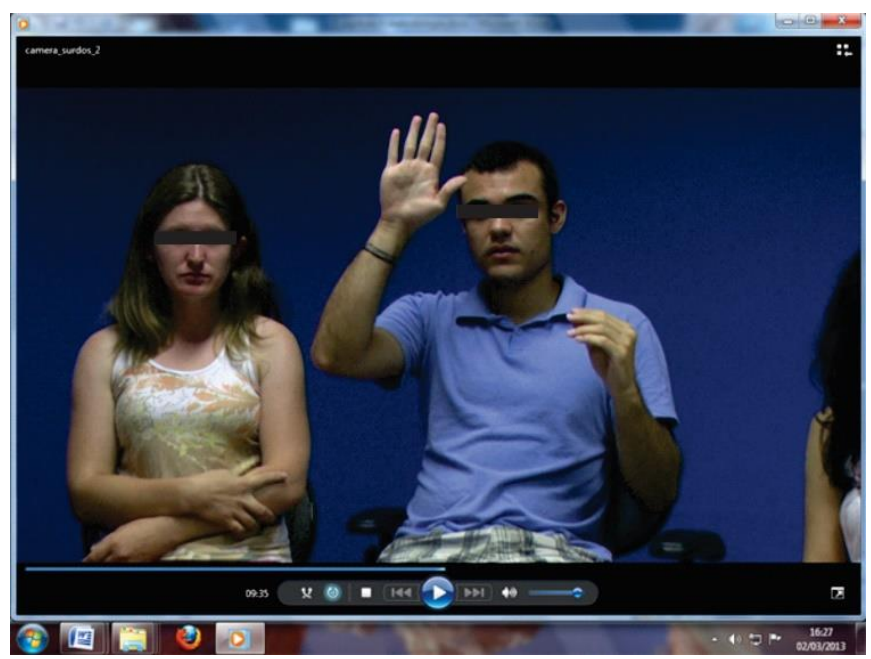

Figura 2: O aluno surdo reivindica o turno, mas é ignorado

Fonte: Os autores
Realização:
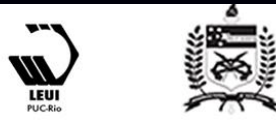


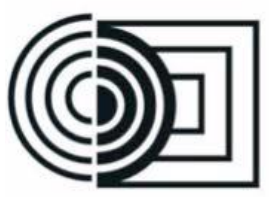
CINAHPA $16^{\circ}$ Ergodesign - Congresso Internacional de Ergonomia e Usabilidade de Interfaces Humano Tecnológica: Produto, Informações Ambientes Construídos e Transporte

$16^{\circ}$ USIHC - Congresso Internacional de Ergonomia e Usabilidade de Interfaces Humano Computador

CINAHPA | 2017 - Congresso Internacional de Ambientes Hipermídia para Aprendizagem.

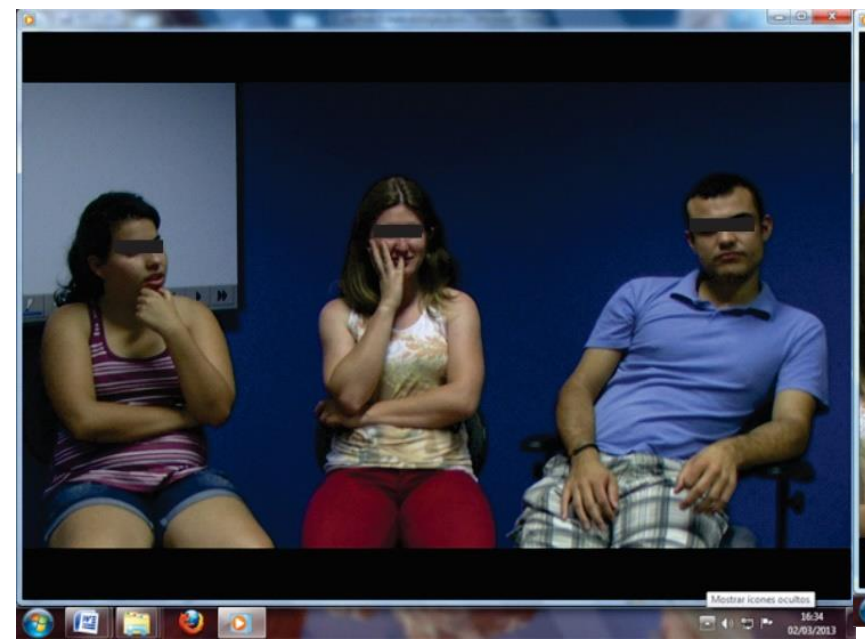

Figura 3: Ingrid (C) perde o turno e desiste de falar

Fonte: Os autores

Rodrigo demonstra pela expressão facial que não gostou, mas ninguém percebe e o debate parece seguir seu curso natural. Os alunos surdos acompanharão pelas intérpretes até que tenham sua chance de falar novamente. Os ouvintes detêm a voz, longos turnos se passarão até que o turno volte ao aluno surdo. Quem fala mais, tem mais poder [CALDAS-COUTHARDT, 2012].

Embora as câmeras tenham captado a exclusão, a tomada de turnos indicou momentos ricos de compreensão, com marcas de tolerância, vindas especialmente da parte dos alunos ouvintes que conheciam o código Libras. Os alunos surdos também demonstraram essa tolerância, concedendo o turno ao ouvinte em determinadas situações, como se vê na Figura 4.

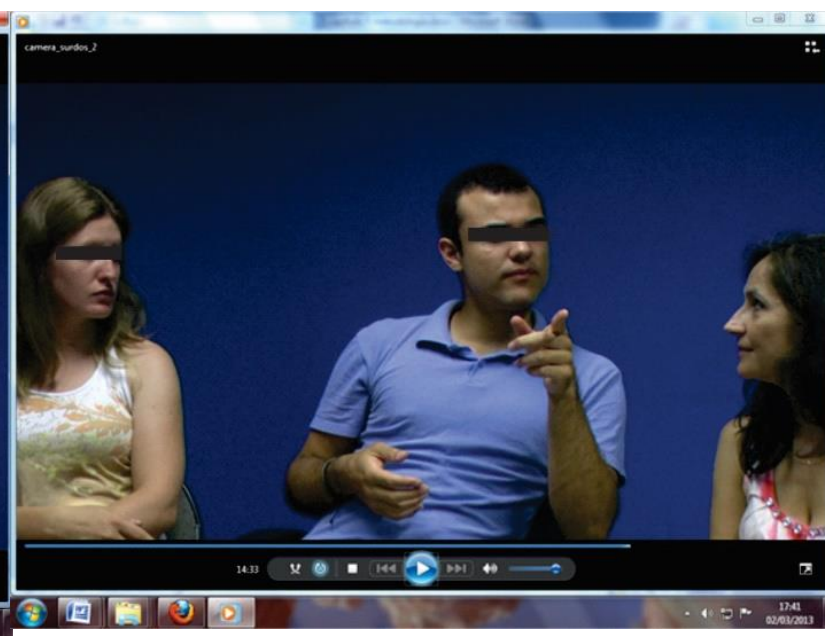

Figura 4: O aluno surdo concede o turno ao colega ouvinte

Fonte: Os autores
A tentativa de estabelecer regras para a conquista do turno proposta inicialmente por um aluno surdo não resultou, porque elas logo foram esquecidas no calor da discussão. $\mathrm{O}$ aluno se queixa. $\mathrm{O}$ sinal "chato" é registrado pela câmera exclusiva por três vezes. A moderadora e as intérpretes precisam se impor para salvaguardar o lugar dos surdos.

$\mathrm{O}$ experimento de todas as narrativas ao mesmo tempo ofereceu a oportunidade de averiguar-se preferências. A narrativa mais confortável para conhecer o conteúdo, segundo seis entre os oito participantes, foi a Narrativa Dissertativa (N1) e a menos confortável a que apresentou Contos (N2). A escolha majoritária por surdos e ouvintes recaiu sobre o gênero dissertativo, porque, na fala dos alunos surdos:

a) Pode-se voltar e entender melhor, ter uma nova interpretação;

b) Pode-se entender mais claramente;

c) Sente-se tranquilidade. Dá para entender e se sentir bem.

Nas razões dos ouvintes, a ideia de entender também está presente:
Realização:

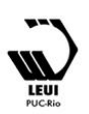




\section{$16^{\circ}$ \\ ERGODESIGN USIHC CINAHPA}

a) É melhor para entender, a HQ e os contos complementam;

b) O texto é mais sucinto e prático, passando mais informação em menos tempo;

c) Porque o entendimento ficou muito mais claro.

Apesar de preferida, a Narrativa Dissertativa teve seu índice de rejeição. Para dois alunos ouvintes foi considerada menos confortável por ser "muito extensa", sem atrativos, tornando-se "cansativa e maçante". Um deles preferiu a HQ pelo caráter "pedagógico", o outro elegeu a forma de Contos como mais confortável, "porque entretém, dá vontade de continuar lendo e, além disso, mostra a utilidade prática do conteúdo".

Os Contos foram avaliados como menos confortáveis para a aprendizagem. Foram considerados "extensos, longos, lentos, com poucas ilustrações". Pelo discurso analisado, foram considerados menos confortáveis porque:
a) Cansou para ler
b) É mais difícil, mais lento e muito longo
c) Porque tinha poucas ilustrações

A troca de impressões por meio do chat foi outro ponto observado na experiência. Esperava-se que o chat fosse um momento de extrema descontração entre os alunos, livres das regras da sala de aula presencial. As cinco páginas coletadas posteriormente apenas com os diálogos desta função específica demonstraram que o chat não foi amplamente utilizado.

A conversa girou apenas entre dois ouvintes não conhecedores de Libras. Os alunos surdos não utilizaram a função nessa e nem na maioria das quatro sessões de experimento. A exceção coube à primeira experiência, quando sua presença foi identificada no chat, mas sem que eles falassem ou buscassem compartilhar informações. Apenas entravam e saíam do ambiente, como se quisessem ver o que o grupo conversava, sem emitir sua opinião. $16^{\circ}$ Ergodesign - Congresso Internacional de Ergonomia e Usabilidade de Interfaces Humano Tecnológica: Produto, Informações Ambientes Construídos e Transporte

$16^{\circ}$ USIHC - Congresso Internacional de Ergonomia e Usabilidade de Interfaces Humano Computador

CINAHPA | 2017 - Congresso Internacional de Ambientes Hipermídia para Aprendizagem.

Foi de interesse desta pesquisa verificar o que os participantes destacaram com relação às atividades preparadas para avaliá-los. Ficou demonstrado que o surdo não pode realizar atividade com espaços a completar. Sem conhecer o significado de determinada palavra proposta na atividade, por exemplo, o surdo Felipe disse que decidiu "escolher por escolher". A avaliação da aprendizagem demonstrou que os surdos apresentaram índice de acertos das atividades menor do que os ouvintes, em uma ou duas questões, conforme a narrativa experienciada.

\section{Considerações Finais}

Embora existam muitas vantagens oferecidas por sistemas hipermídia, como permitir a superação de limitações provenientes das diferenças cognitivas, sensoriais e motoras, não se pode deixar de lembrar que a eficácia da interação humanocomputador depende de se conhecer os fundamentos de acessibilidade específica requerida.

Os sistemas podem avançar ancorados nas diferenças dos alunos, moldando-se a perfis com características móveis, com maior ou menor incidência de uma e outra, conforme a linguagem desejada. A Libras pode ser ampliada em detrimento do português e vice-versa; tamanhos de fontes, tipos, imagens estáticas ou em vídeo configurariam opções variáveis ao desejo do receptor.

O debate das ideias estimula o desafio de pensar o 'devir' à narrativa em hipermídia: conseguirá essa narrativa, em seu labirinto de informações - com seus inúmeros hiperlinks e a quebra da linearidade da narrativa tradicional - manter a verossimilhança da narrativa linear, sendo ela própria um mosaico? A experiência com o AVEA WebGD Acessível mostrou que sim, e no mesmo nível para surdos e ouvintes, com destaque para o bilinguismo como poderosa ferramenta de inclusão.

As observações e sugestões aqui relatadas contribuem para consolidar o modelo em 


\section{$16^{\circ}$ \\ ERGODESIGN USIHC CINAHPA}

hipermídia que vem sendo forjado ao longo dos últimos anos, e para o qual não se vislumbra um desenho estático nestes tempos de sociedade em constante mutação.

\section{BIBLIOGRAFIA}

BRUCKMEIER, J.; HARRÉ, R. Narrativa: problemas e promessas de um paradigma alternativo. Psicologia, Reflexão e Crítica, vol.16, $\mathrm{n}^{\circ}$ 3. Porto Alegre, 2003. Disponível em http://www.scielo.br/scielo.php?pid=S010279722003000300011\&script=sci_arttext. Acesso em nov. 2016.

CAMPBELL, S. Múltiplas faces da inclusão. Rio de Janeiro: Wak Editora, 2009.

CALDAS-COUTHARD, C. R. Narrativas e Análise Crítica do Discurso. [mensagem pessoal] Mensagem recebida por: <Silvia Quevedo>. em nov. 2012.

MURRAY, J. H. Hamlet no Holodeck: O futuro da narrativa no ciberespaço. Itaú Cultural, Unesp, São Paulo: 2003.

SANTAELLA, L. Linguagens líquidas na era da mobilidade. São Paulo: Paulus, 2007.

Agradecimentos à CAPES e ao CNPQ pelo apoio a esta pesquisa. $16^{\circ}$ Ergodesign - Congresso Internacional de Ergonomia e Usabilidade de Interfaces Humano Tecnológica: Produto, Informações Ambientes Construídos e Transporte

$16^{\circ}$ USIHC - Congresso Internacional de Ergonomia e Usabilidade de Interfaces Humano Computador

CINAHPA | 2017 - Congresso Internacional de Ambientes Hipermídia para Aprendizagem. 